\title{
Coordenadoras pedagógicas e diversidade: entre percursos formativos e práticas na escola básica*
}

\section{Pedagogical coordinators and diversity: between training courses and practices at elementary school}

\author{
Wilma de Nazaré Baía Coelho** \\ Carlos Aldemir Farias da Silva**
}

\begin{abstract}
RESUMO
O artigo apresenta práticas que conformam a formação e a atuação de coordenadoras pedagógicas de cinco escolas da periferia do município de Belém, estado do Pará, tendo por base as novas diretrizes curriculares nacionais para a formação inicial e continuada dos profissionais do magistério da Educação Básica, de 1 de julho de 2015. Nossa intenção é analisar como o percurso formativo desses profissionais (des)favorece práticas pedagógicas atentas aos "sentidos de diversidade e desigualdade". Analisaremos os processos formativos e as práticas pedagógicas das coordenadoras atuantes em escolas públicas de Ensino Fundamental e Médio, tendo a compreensão de que a interferência de técnicos pedagógicos sobre os procedimentos teóricos e metodológicos é decisiva para a condução do trabalho pedagógico de uma instituição escolar, uma vez que estes profissionais figuram entre os que atuam na definição de políticas educacionais internas. Entre as conclusões realizadas, constatamos, por meio de documentos escritos e orais, o descompasso entre a formação para uma escola ideal e o parco conhecimento
\end{abstract}

DOI: $10.1590 / 0104-4060.49152$

* Pesquisa intitulada "Sociabilidades adolescentes: cor e hierarquias no ambiente escolar (2014-2017)"; financiamento do Conselho Nacional de Desenvolvimento Científico e Tecnológico (CNPq).

** Universidade Federal do Pará. Instituto de Filosofia e Ciências Humanas. Belém, Pará, Brasil. Rua Augusto Corrêa, 01 - Guamá. CEP 66075-110. E-mails: wilmacoelho@yahoo.com.br; carlosfarias1@gmail.com. 
das relações contextuais de desigualdades, afetando estruturalmente as práticas pedagógicas.

Palavras-chave: Coordenadoras pedagógicas. Escola Básica. Práticas. Diretrizes Curriculares. Sentidos de diversidade e desigualdade.

\begin{abstract}
This article presents practices that form the base of pedagogical coordinators' formation and activities. The subjects work in five schools in the outskirts of Belém (Pará, Brazil), and try to imbed their methods on the new national curriculum guidelines for elementary teachers' initial and ongoing formation, of July $1^{\text {st }}, 2015$. We intend to analyze how these professionals' formation favors (or does not) teaching practices attentive to "the meanings of diversity and inequality". We will analyze educational processes and teaching praxes of pedagogical coordinators who work at public primary and secondary schools, because we understand that pedagogical technicians grounded in theoretical and methodological procedures are crucial to the conduction of educational labor at school, since those professionals are among the ones who deal with the definition of internal educational policies. Through written and oral documents, conclusions suggest that the mismatch between formation for an ideal school and the meager knowledge of contextual relations of inequality structurally affects pedagogical practices.
\end{abstract}

Keywords: Pedagogical coordinators. Elementary school practices. Curriculum guidelines. The meanings of diversity and inequality.

\title{
Introdução
}

O trabalho da coordenação pedagógica ${ }^{1}$, no âmbito escolar, centra-se em atividades de planejamento das ações cotidianas docentes, discentes e familiares. A prática pedagógica da coordenação se sustenta no currículo formal e na legislação vigente, no sentido de mediar, "revelar/desvelar" os significados dos documentos curriculares para os agentes escolares, com o propósito de crítica e de adequação à dinâmica escolar com vistas ao compromisso de um ensino-aprendizagem de qualidade, nas instâncias em que a escola se vincula. Ainda entre suas ações, ela também intervém no processo educativo e nas atividades

1 Nas próximas seções do artigo, utilizar-nos-emos da sigla $\mathrm{CP}$ ao nos referirmos à coordenadora pedagógica, coordenadoras pedagógicas ou coordenação pedagógica. 
pedagógicas, tanto nas formulações quanto na reestruturação das práticas pedagógicas (OLIVEIRA; GRISPUN, 2013; PLACCO; ALMEIDA; SOUZA, 2011; GLATTER, 1992; DOWBOR, 2001).

Este artigo adota as ponderações conceituais de Conceição (2010), Coelho e Padinha (2013), para quem este profissional atua como mediador pedagógico no âmbito educacional, pois seu trabalho constitui-se num nível de complexidade na confluência entre a família e os agentes escolares, especialmente no enfrentamento das dificuldades de aprendizagem e outras necessidades educativas. Assim, em consonância com a literatura especializada, a qual entende, ainda, que o coordenador pedagógico se constitui como um agente fundamental nos processos didático-pedagógicos atinentes aos docentes e aos discentes na escola. Consideramos, destarte, a premissa de que esse profissional assume um lugar estratégico na formulação das políticas educacionais no contexto escolar, uma vez que estes figuram entre os que atuam na definição dessas políticas.

Os cursos de formação dos profissionais que atuam na Educação Básica têm sido devedores de uma formação mais prática, pois esses cursos apresentam-se majoritariamente em uma perspectiva teórica; porém, com uma parca experiência prática, em especial os cursos de Pedagogia. Em contrapartida, as demais licenciaturas centram-se quase que exclusivamente em suas áreas específicas e menos em dimensões pedagógicas (GATTI; BARRETO; ANDRÉ, 2011; SAVIANI, 2009).

Coelho e Padinha (2013) pontuam o descompasso entre a ação pedagógica da coordenadora na escola e a ausência de reflexão conceitual para a compreensão dos processos complexos oriundos do cotidiano escolar. Ao considerar o avanço das discussões sobre a escola e sobre a legislação vigente por meio de diversos suportes, inclusive a ampliação de acesso às informações pela rede mundial de computadores, retornamos às escolas belenenses para a ampliação do entendimento acerca desse aparato conceitual na relação entre os processos formativos e a prática pedagógica.

Em consonância com as novas DCN, os profissionais do magistério da Educação Básica requerem a constituição de repertório de conhecimento cultural acerca da prática educacional atinente aos "sentidos de diversidade e desigualdade", em todas as etapas e modalidades deste nível de ensino. Comunga-se da compreensão de que a prática pedagógica das $\mathrm{CP}$ auxilia diretamente na definição das políticas educacionais internas, pois a sua interferência nos procedimentos teóricos e metodológicos costuma ser crucial para a condução do trabalho pedagógico de uma instituição escolar, contribuindo para o enfrentamento da diversidade étnico-racial, sexual e de gênero, conforme a Resolução n. 2/2015, nos artigos 3, $5,8,12,13,14$ e 15 . 
Consideramos, nesta inflexão, que a ausência de enfrentamento pedagógico em relação aos "sentidos de diversidade e desigualdade" como marcadores de sociabilidades adolescentes na escola colabora para o silenciamento do preconceito e a manutenção das hierarquias sociais, os quais exigem uma formação consubstanciada da CP no âmbito escolar. No sentido apontado por Juarez Dayrell (2007, p. 1111), para quem "a sociabilidade, para os jovens, parece responder às suas necessidades de comunicação, de solidariedade, de democracia, de autonomia, de trocas afetivas e, principalmente, de identidade".

Neste artigo, objetivamos analisar como o percurso formativo (des)favorece práticas pedagógicas atentas "aos sentidos de diversidade e desigualdade". Tal análise auxilia a compreensão dos procedimentos metodológicos da prática pedagógica de cinco coordenadoras da Educação Básica. Não se trata de realizar "julgamentos evasivos"”, mas de problematizar especificamente em que nível esse percurso formativo interfere na prática pedagógica em consonância com a legislação vigente, a qual elucida a necessidade de os profissionais da educação enfrentarem pedagogicamente os "sentidos de diversidade e desigualdade" na prática pedagógica cotidiana.

Para o entendimento desses procedimentos metodológicos, entrevistamos cinco CP durante o primeiro semestre de 2016, por uma média de uma hora e meia, com ênfase em duas dimensões principais, quais sejam: em relação ao percurso formativo (leituras, disciplinas teórico-didáticas cursadas, fundamentação teórica no trabalho, conhecimento da legislação vigente, relações com estudo e redes sociais); e em relação às práticas (dificuldades, objetivo e metodologia, relações de sociabilidades entre crianças e adolescentes no trabalho com diversidade e desigualdade).

Para a constituição dos quadros síntese apresentados a seguir, foram utilizadas as categorias estruturantes que compuseram os testemunhos dessas profissionais. Após a organização e sistematização dos dados, recorremos ao estudo de Bardin (2000) para a realização da análise de conteúdo, com vistas a extrair das entrevistas categorias e unidades basilares que consubstanciaram os argumentos para a compreensão do percurso formativo e a relação com as práticas. Desse modo, a reflexão ora realizada apresenta um debate em aberto, porquanto o objeto considerado apresente diversas dimensões de análise, esta relativa ao percurso formativo e às práticas, constituem-se tão somente duas dessas dimensões.

2 Coelho e Padinha (2013). 


\section{Perfil das coordenadoras pedagógicas}

Trabalhamos, neste segmento da pesquisa, com cinco $\mathrm{CP}^{3}$. Trata-se de um grupo homogêneo: quatro delas formaram-se em instituições públicas, acumulam mais de dez anos de experiência, autodeclaram-se pardas e afirmam não ter sofrido qualquer tipo de discriminação. Diferenciam-se no que concerne à faixa etária (entre 20 e 50 anos) e à renda familiar (entre cinco e dez salários mínimos), bem como na formação (há especialistas e uma mestra). Todas destinam uma a três horas por dia para os estudos e tempo similar às redes sociais. Para uma compreensão amiúde dos percursos e das práticas, trabalharemos os dois quadros a seguir, cada um com suas especificidades e detalhamento:

QUADRO 1 - PERCURSO FORMATIVO E A RELAÇÃO COM A PRÁTICA PEDAGÓGICA

\begin{tabular}{|l|l|l|l|}
\hline $\begin{array}{l}\text { Coordenadoras } \\
\text { Pedagógicas }\end{array}$ & $\begin{array}{l}\text { Nível de conhecimen- } \\
\text { to sobre a Resolução } \\
\text { CNE/CP N 02/2015 }\end{array}$ & Aporte teórico & $\begin{array}{l}\text { Nível de conhecimento/forma- } \\
\text { ção inicial e relação com a prá- } \\
\text { tica }\end{array}$ \\
\hline Rosa & Desconhecimento & $\begin{array}{l}\text { Matérias } \\
\text { televisivas }\end{array}$ & $\begin{array}{l}\text { Lê-se muito, mas a prática é pou- } \\
\text { ca; não se aprende a ser coordena- } \\
\text { dora na universidade. }\end{array}$ \\
\hline Margarida & Desconhecimento & $\begin{array}{l}\text { Paulo Freire e } \\
\text { vídeos da Rede } \\
\text { Globo }\end{array}$ & $\begin{array}{l}\text { Aprendi na graduação sobre a pe- } \\
\text { dagogia do afeto, mas para coor- } \\
\text { denação pedagógica a formação é } \\
\text { deficiente; foi bem difícil realizar } \\
\text { esse trabalho na escola. }\end{array}$ \\
\hline Hortência & Desconhecimento & $\begin{array}{l}\text { Textos da } \\
\text { internet }\end{array}$ & $\begin{array}{l}\text { O curso de graduação é muito teó- } \\
\text { rico e pouca prática; a experiência } \\
\text { com a coordenação pedagógica } \\
\text { veio com a minha entrada na es- } \\
\text { cola. }\end{array}$ \\
\hline Dália & Desconhecimento & $\begin{array}{l}\text { Maria Tereza } \\
\text { Maldonado }\end{array}$ & $\begin{array}{l}\text { A graduação me auxiliou a com- } \\
\text { preender o universo escolar por } \\
\text { meio da Fenomenologia; não } \\
\text { aprendi a ser coordenadora na uni- } \\
\text { versidade. }\end{array}$ \\
\hline Orquídea & Desconhecimento & $\begin{array}{l}\text { Celso Vascon- } \\
\text { celos e Paulo } \\
\text { Freire }\end{array}$ & $\begin{array}{l}\text { Ocurso de graduação é aquém do } \\
\text { aprendi a ser coordenadora no dia } \\
\text { a dia. }\end{array}$ \\
\hline
\end{tabular}

FONTE: Dados da pesquisa oriundos das entrevistas realizadas no primeiro semestre de 2016.

3 Para preservar a identidade das coordenadoras entrevistadas, denominamo-las com nomes fictícios. 
No que diz respeito à pergunta sobre a Resolução CNE/CP N ${ }^{0}$ 02/2015 , as coordenadoras tinham notícia; contudo, o desconhecimento era geral em relação a ela. Desconhecem seu teor, seu conteúdo e há ausência de interesse em relação aos impactos da Resolução na escola. O conhecimento das coordenadoras sobre a legislação vigente é sempre acompanhado de perguntas como: "É a lei das cotas?"; "É a lei sobre a negritude?"; "É aquela que fala sobre a consciência negra?". Assim, as profissionais têm uma vaga ideia do dispositivo legal, embora efetivamente dele não tenham conhecimento. Ao serem instadas sobre a fundamentação teórica de sua prática pedagógica, textos da internet, vídeos e matérias jornalísticas da Rede Globo de televisão são acionados para o trabalho com crianças e adolescentes. As exceções estiveram com aquelas que mencionaram Vasconcelos, Freire e Maldonado.

Quanto à contribuição do percurso formativo e ao auxílio na prática, confirmamos, em nossa pesquisa, até o momento, aquilo que Serpa (2011) pontua sobre a ausência de formação em gestão e a ineficácia dos cursos de graduação para dominar competências e estratégias necessárias à função desempenhada cotidianamente na escola. Entre nossas análises, afirmamos que as CP aprenderam a função na escola, aos trancos e barrancos ou com a experiência das CP mais antigas, haja vista que a formação inicial parece não dar suporte para esta função. Conclusão similar encontramos na pesquisa realizada por Franco (2008) e Cruz, Castro e Lima (2009), cujos resultados enfatizam que as dificuldades encontradas na atuação de CP referem-se a uma formação inicial inconsistente e desprovida de identidade profissional. No quadro, a seguir, pormenorizaremos as práticas pedagógicas.

$\mathrm{O}$ trabalho desenvolvido pelas $\mathrm{CP}$ nas escolas centra-se fundamentalmente em observações do cotidiano escolar e constituem-se em ações devidamente articuladas com um ou mais profissionais em relação às sociabilidades adolescentes presentes no espaço escolar, no virtual e na sala de aula, especialmente no tocante às hierarquias constituídas entre eles - veladas ou não. No tocante às relações de sociabilidades desenvolvidas pelos estudantes, estas se mostraram oscilares $^{5}$, variando entre a afetividade e a agressividade. Para os estudantes, tais relações estão intrinsecamente relacionadas com as semelhanças de gostos e preferências. Nesse sentido, Bourdieu $(2008 ; 1983)$, compreende que a formulação do gosto é um processo completo de aprendizagem e, como tal, produto de

4 Trata-se das novas diretrizes curriculares nacionais para a formação inicial e continuada dos profissionais do magistério da Educação Básica, tendo por base o Parecer CNE/CP N $02 / 2015$, aprovado pelo Conselho Pleno do Conselho Nacional de Educação (CNE), em 9 de junho de 2015, e homologado pelo MEC, em 24 de junho de 2015. Para discussão consubstanciada consultar o artigo de Luiz Fernandes Dourado (2015).

5 Dayrell e Barbosa (2009). 


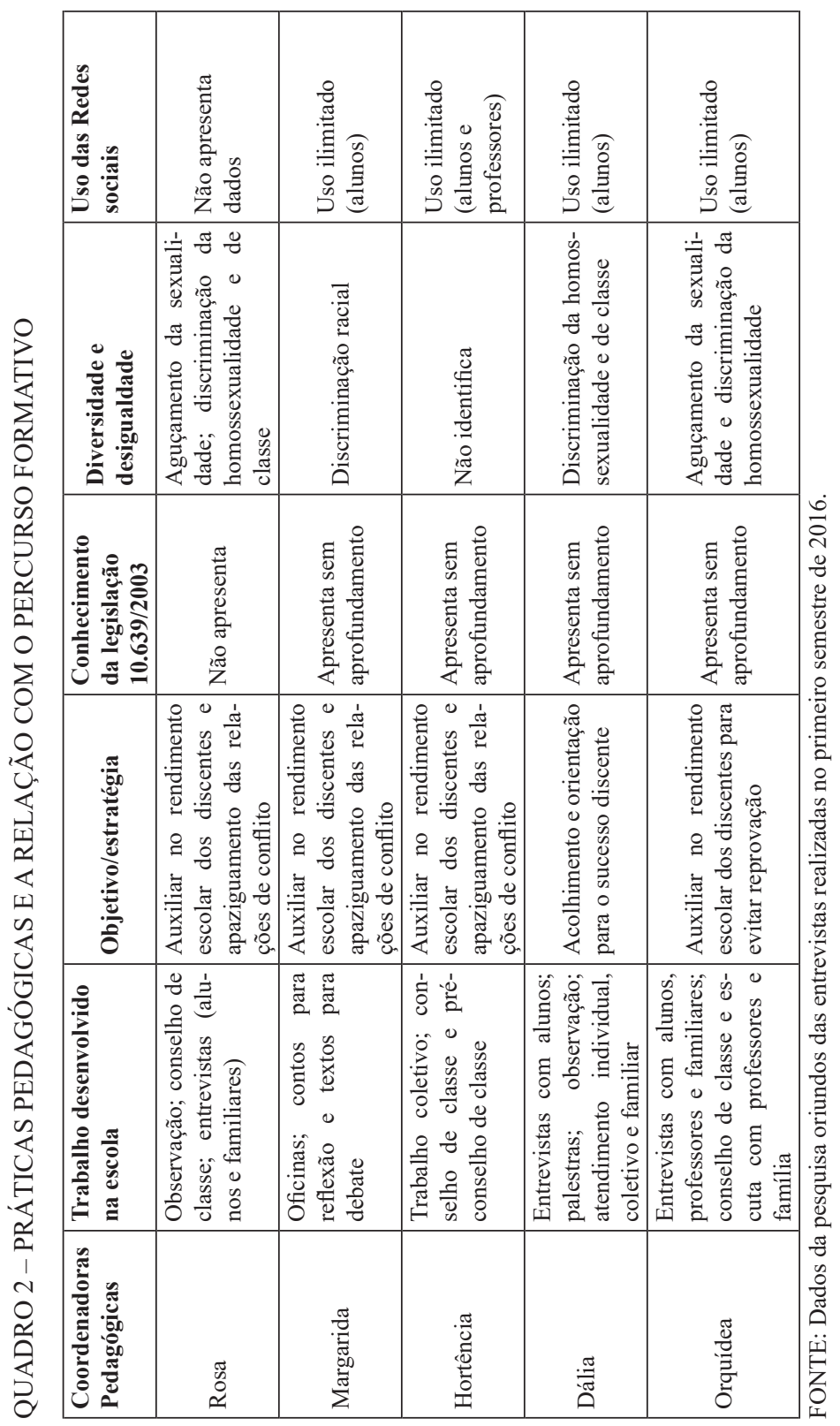


um conjunto de interiorizações que se vão operando no indivíduo, desde a mais tenra idade. O gosto será, assim, um resultado complexo das condições sociais de existência de cada indivíduo e da respectiva trajetória social que cada um vai percorrendo, constituindo parte dessas relações sociais intra e extramuros, situações, em parte, sob a mira das CP, por meio das observações.

O resultado dessas observações coaduna com as demandas advindas dos docentes em relação aos discentes, sobretudo, nas situações de conflito entre os próprios estudantes, como também entre estudantes e professores, dentro e fora do espaço escolar presencial e/ou virtual. O encaminhamento realizado a partir dessas observações consiste em um relatório individual no qual as situações são pormenorizadas e os encaminhamentos pedagógicos realizados. Como se trata de uma ação coletiva, qualquer encaminhamento pedagógico é submetido à ampliação dos integrantes do conselho de classe, como conjunta à ação pedagógica na vida escolar. É uma forma de avaliação de controle da realização da proposta pedagógica no sentido empreendido por Perrenoud (1999) e Carminati (2016).

Após ampla discussão acerca de cada caso, especialmente aqueles relativos ao rendimento escolar, as $\mathrm{CP}$ - quase sem exceção - retornam aos estudantes, aos familiares e aos docentes com ações específicas e pontuais. Oficinas, palestras e debates sobre temas requeridos em função das situações observadas e discutidas no conselho de classe são, quase sempre, objeto de ampla contenda pelas CP, por especialistas externos à escola ou por professores da casa. A intenção do trabalho das CP prioriza o êxito escolar dos estudantes. Em Perrenoud (1999), o êxito ou o fracasso na escola são orientados pelas exigências manifestadas pelos docentes, os quais devem espelhar a legislação vigente de cada país. As $\mathrm{CP}$, a despeito das diversas ações cotidianas, objetivam o rendimento escolar dos discentes, o apaziguamento e a conciliação das relações de conflito, pois, ao fim e ao cabo, rotineiramente, "apagam fogo". As situações são demandadas intensamente, limitando severamente o tempo destinado ao trabalho e ao aprofundamento da temática sobre diversidade e desigualdade na escola.

A necessidade do conhecimento das diretrizes parece imperativa para o trabalho com crianças e adolescentes. No entanto, as diretrizes curriculares nacionais para a educação das relações étnico-raciais e a Lei N ${ }^{\circ} 10.639 / 2003$ não estão incorporadas ao trabalho das coordenadoras, nem fazem parte de seu espectro de conhecimento. Em concordância com Müller e Coelho (2013, p. 30), ao mencionarem a lei há três anos, afirmavam com assombro o "desconhecimento por parte de alguns professores e gestores do que emana a Lei $\mathrm{N}^{o} 10.639 / 2003$, apesar de ter completado 10 anos de existência". Nesse caso, reitera-se o desconhecimento do dispositivo legal após 13 anos.

$\mathrm{O}$ uso das redes sociais incorporou-se no cotidiano de estudantes, de professores e de CP. Definitivamente, tudo ou quase tudo - do universo escolar às 
situações prosaicas - é tratado, discutido e exposto nas redes sociais. Todos os assuntos são midiatizados, inclusive a vida pessoal de discentes e de docentes. Neste cenário, ninguém é poupado; as situações são superdimensionadas e todos parecem ter opinião sobre tudo. As brigas e desacertos iniciados presencialmente em sala de aula ganham vida, adeptos e opositores nas redes sociais. O contrário também ocorre: o que é virtual torna-se presencial.

A escola há de redimensionar sua estratégia de ensino, pois esse espaço merece estudo e atenção por parte dos agentes escolares, uma vez que a presença nas redes sociais dos estudantes é infinitamente maior do que na sala de aula. Isso se coloca em consonância com Setton $(2015$, p. 8), ao afirmar que "junto com a família, a religião e a escola (entre outras instituições), as mídias funcionam como instâncias transmissoras de valores, padrões e normas de comportamentos e também servem como referências identitárias". A utilização do virtual não é mérito apenas dos estudantes. Professores e, neste caso, as CP dedicam às redes sociais o mesmo tempo destinado aos estudos para o trabalho pedagógico na escola.

\section{Sentidos de diversidade e desigualdade}

Discutir diversidade e desigualdade na escola não é tarefa fácil, sobretudo na inexistência de repertório teórico-conceitual para o enfrentamento da temática. Quando se pensa em diversidade, pensa-se em negro, mulher, indígena, como se a diversidade se limitasse a esses grupos sociais. Em verdade, todos os grupos devem constituir a diversidade para superar hierarquizações e desigualdades.

Em nossa sociedade, identidade, alteridade, diversidade, desigualdade, cooperação, hierarquização e alienação são ações e produções sociais e, como tais, estão sujeitas a alterações e subversões como alternativas de novas formas de sociabilidades (IANNI, 2004; CANDAU, 2012). Para tal alteração, por serem contradições sociais veladas, terão de ser objeto de constantes problematizações na sociedade, e na escola não deve ser diferente.

Para as CP, a sexualidade na escola entre os adolescentes se constitui em comportamento latente. Ações e discursos homofóbicos, de discriminação racial e de classe são constantes nos corredores, nos intervalos, nas salas de aula, nos muros, nos banheiros e nas redes sociais. Esses comportamentos, embora frequentes, são identificados pelos profissionais como nocivos e perniciosos, mas não sofrem intervenção devido à ausência de referenciais para o enfrentamento pedagógico no trato dessas situações. Conforme o depoimento da coordenadora: 
"Os professores, assim como nós, não têm conhecimento para tratar de assuntos relacionados à discriminação e à diversidade" (informação verbal) ${ }^{6}$.

Os depoimentos das CP sobre o que dizem os estudantes, a seguir, são reveladores em relação ao preconceito de gênero, de classe e de raça. "Você sabe de uma coisa, o meu irmão veio me buscar aqui e ele é homossexual; muitos dos meus colegas queriam me bater por causa disso" (informação verbal) ${ }^{7}$. "Houve o caso de uma menina homossexual que foi falar alguma coisa pelo grupo de WhatsApp deles e um colega agiu de forma preconceituosa com ela. Ela não gostou, e do WhatsApp foi parar no Facebook e terminou na sala de aula" (informação verbal) ${ }^{8}$.

Não há limite na pulverização da discriminação e do preconceito. O que é virtual se concretiza na sala de aula e vice-versa. Nesse panorama, os testemunhos revelam o quão ostensivo é o preconceito contra os homossexuais na escola. O comportamento homofóbico dos estudantes revela a intolerância não somente contra os homossexuais, mas contra o seu parente próximo.

Se considerarmos que "homofobia significa aversão irreprimível, repugnância, medo, ódio, preconceito que algumas pessoas ou grupos nutrem contra os homossexuais, lésbicas, bissexuais e transexuais, o indivíduo que pratica tal ação denomina-se homofóbico" (DICK; FERREIRA; CERVEIRA, 2016, p. 45). Esses processos de normalização geram diferentes processos de discriminação e subalternização. Para mudar essa lógica, diversos estudos acadêmicos são unânimes na defesa de uma educação diversa, plural e inter/multicultural (CANDAU, 2011).

Fazemos eco às inflexões de Michel Serres (2013), quando trata das alterações nas relações de sociabilidades e a ação pedagógica a partir dos "polegares". Contudo, essa "revolução digital" do mundo global para o universo escolar alterou as relações de comunicação e aproximou as culturas, mas não parece ter alterado o respeito ao diferente de si e o julgamento de valor na hierarquia entre os grupos sociais, especialmente aqueles perseguidos historicamente (COELHO; SILVA, 2015, p. 697).

As relações interdependentes sociedade-escola e escola-sociedade são

[...] abordadas numa via de mão dupla, uma vez que os estudantes, ao trazerem as representações incorporadas socialmente por meio das mídias para a escola, impactam e modificam as relações pedagógicas e de agru-

6 Coordenadora Orquídea, em entrevista, no primeiro semestre de 2016.

7 Coordenadora Rosa, em entrevista, no primeiro semestre de 2016.

8 Coordenadora Orquídea, em entrevista, no primeiro semestre de 2016. 
pamentos das representações conflituosas no âmbito escolar (COELHO; SILVA, 2015, p. 687).

A discriminação em relações aos alunos pobres também assume lugar de destaque nas escolas: "Discriminam-se os alunos que são pobres, especialmente pelo modo como se vestem" (informação verbal)". "A discriminação é forte com os pobres; os pobres sofrem mais" (informação verbal) ${ }^{10}$.

O espaço da escola tem sido palco de múltiplas hierarquias. Veladas ou não, elas estão presentes. Essas hierarquias são percebidas especialmente por grupos específicos no âmbito escolar. Com a ampliação de vagas, sujeitos de diferentes classes sociais são inseridos por meio de ações políticas inclusivas, no entanto alguns grupos mais familiarizados com aquele espaço entendem-no como seu. Desse modo, os "donos do lugar", ao perceberem a ampliação de acesso e de direitos, começaram a resistir à presença de pessoas de outros grupos sociais e étnicos.

Nas escolas pesquisadas, essa realidade tem sido recorrente. Os depoimentos são reveladores desse "desconforto" com a presença desses novos agentes. Inclusive no desencadeamento daquilo que Mendonça e Jordão (2014) chamaram de "nojo de pobre". Trata-se de um comportamento inapropriado e reprovável, pois abriga a hierarquia de "superiores" e "inferiores". Tais grupos, objeto dessa "repulsa", são julgados pelo que vestem, pelos artefatos tecnológicos que portam, pelo que falam e pelo rendimento escolar apresentado.

Embora as $\mathrm{CP}$ atestem isenção de ações discriminatórias em relação a si mesmas, a escola não está isenta de tais ações, as quais refletem dimensões bem conhecidas sobre a realidade brasileira. De maneira especial nas contradições a que estamos submetidos, os depoimentos a seguir elucidam algumas dessas dimensões: "A minha família era como se não quisesse falar que existia o lado negro na família" (informação verbal) ${ }^{11}$. "A discriminação racial acontece na educação infantil" (informação verbal) ${ }^{12}$.

A coordenadora Margarida, detentora de um conhecimento circunstanciado sobre a temática étnico-racial por meio de especialização e na profissão há duas décadas, ainda reproduz um discurso pouco apropriado para falar de sua ascendência afro-brasileira. Essa coordenadora reconhece a existência da discriminação muito fortemente na educação infantil, universo amplamente estudado por Cavalleiro (2000), Fazzi (2004) e Amaral (2013).

9 Coordenadora Rosa, em entrevista, no primeiro semestre de 2016.

10 Coordenadora Dália, em entrevista, no primeiro semestre de 2016.

11 Coordenadora Margarida, em entrevista, no primeiro semestre de 2016.

12 Idem. 
A escola, como lócus privilegiado de formação, constitui-se potencialmente em um espaço onde as desigualdades e a discriminação, sobretudo na infância, devem ser combatidas e enfrentadas por meio de ação pedagógica. O combate ao preconceito, exige uma intervenção pontual e qualificada por parte dos agentes escolares e, por conseguinte, das coordenadoras pedagógicas.

A necessidade de se preparar pedagogicamente para o reconhecimento e enfrentamento da discriminação para os "sentidos de diversidade", na escola, requer capacitação continuada que habilite as $\mathrm{CP}$ no trabalho cotidiano com crianças e adolescentes, que esteja consubstanciado na legislação, na literatura especializada e no conhecimento aprofundado em relação a esses agentes, de modo a subverter "a desigualdade e a hierarquização", como advertem Ianni (2004) e Candau (2012). Lidar com a formação da identidade constitui-se em um processo complexo e, quando vem acompanhado do medo ao preconceito e às dificuldades nas relações sociais, pode se tornar uma fase de profundo sofrimento, ocasionando dificuldades no aprendizado e, em alguns casos, como em duas dessas escolas, em abandono. O conhecimento sobre os "sentidos de diversidade e desigualdade" diminui a ignorância e provê aos profissionais da educação a oportunidade de repensar suas práticas.

\section{Considerações finais}

Mesmo conscientes do trabalho realizado pelas $\mathrm{CP}$, especialmente aqueles relacionados ao debate quanto aos direitos e aos deveres dos estudantes por meio de oficinas, palestras, atendimento familiar, individual e coletivo. Considerando a reflexão de Gaudêncio Frigotto (2005) de que a aprendizagem dos alunos não depende unicamente da competência da equipe docente e pedagógica, pois, para este autor, é impossível superar as desigualdades do âmbito educativo e cultural sem, concomitantemente, superar a materialidade de relações sociais que a produziram. Ainda reconhecendo o investimento e o vigor do trabalho das $\mathrm{CP}$, que não podem ser subdimensionados, existe, no entanto, um descompasso entre os processos formativos e as práticas pedagógicas que desfavorecem o desenvolvimento didático e epistemológico das ações realizadas no âmbito escolar com discentes e docentes.

Nessas duas últimas décadas, a despeito do avanço da temática por meio de produção consubstanciada em teses e dissertações nos cursos de formação continuada, as profissionais entrevistadas apresentam diminuto conhecimento acerca da literatura especializada, e a Resolução No 02/2015 não lhes parece 
familiar; porquanto inexiste aprofundamento, o que dificulta a percepção e a subversão de situações de "violência simbólica" (BOURDIEU, 2012) presencial ou virtual corrente ou cotidiana na escola.

A partir da inflexão realizada, constatamos resultado similar em estudo já realizado sobre CP por Coelho e Padinha (2013), no que concerne à fragilidade dos cursos de formação inicial e à ausência de nexo entre o objeto do conhecimento de sua área e a prática pedagógica. Em nossa análise, os dados revelaram, por meio de documentos orais e escritos, o descompasso entre os percursos formativos para a escola ideal e o parco conhecimento das relações contextuais de desigualdades, afetando estruturalmente as práticas pedagógicas e o enfrentamento assertivo para o trabalho com os "sentidos de diversidade e desigualdade".

A formação dessas profissionais também é devedora de uma gênese da práxis que considera a escola como um espaço de sociabilidade, no qual a diversidade se faz presente, assim como na sociedade em geral (COELHO; SILVA, 2015). Conhecer de maneira consubstanciada a legislação parece imperativo para proposições de encaminhamentos pedagógicos consubstanciados em não somente se considerar nociva e perniciosa a seletividade e a normatização de um padrão hegemônico de masculinidade, mas também de propor alterações estruturais na dinâmica e no conteúdo escolar. Tal alteração poria em suspense a naturalização da discriminação e da desigualdade naquilo que Lilian Schwarcz advertiu, em função de nosso passado no Brasil no tocante às relações étnico-raciais, que fizeram da "desigualdade uma etiqueta internalizada e da discriminação um espaço não formalizado" (SCHWARCZ, 1998, p. 184).

É função da escola, entre outras atribuições que lhe são devidas, desenvolver um saber sensível que comporte a problematização das experiências concretas dos estudantes, refletindo sobre a vivência desses agentes no ambiente virtual e a relação com o presencial para a ação efetiva na sala de aula e fora dela, para o enfrentamento do preconceito e da discriminação. Se considerarmos atos discriminatórios como construtos sociais, portanto, sujeitos a processos de socialização na incorporação e na exteriorização, esses mesmos processos podem ser subvertidos. A escola agradece.

\section{REFERÊNCIAS}

AMARAL, A. C. T. A infância pequena e a construção da identidade étnico-racial na educação infantil. 2013. 227f. Tese (Doutorado em Educação) - Setor de Educação, Universidade Federal do Paraná, Curitiba, 2013. 
BARDIN, L. Análise de conteúdo. Tradução de Luís Antônio Reto e Augusto Pinheiro. Lisboa: Edições 70, 2000.

BOURDIEU, P. A distinção: crítica social do julgamento. Tradução de Daniela Kern e Guilherme J. F. Teixeira. São Paulo: Edusp; Porto Alegre: Zouk, 2008.

BOURDIEU, P. O espaço social e a gênese das "classes". In: BOURDIEU, P. O poder simbólico. Rio de Janeiro: Bertrand Brasil, 2012.

BOURDIEU, P. Gostos de classe e estilos de vida. In: ORTIZ, R. (Org.). Pierre Bourdieu: sociologia. São Paulo: Ática, 1983. p. 82-121.

BRASIL. Resolução CNE/CP No 02/2015, de $1^{\circ}$ de julho de 2015. Define as diretrizes Curriculares Nacionais para a formação inicial em nível superior (cursos de licenciatura, cursos de formação pedagógica para graduados e cursos de segunda licenciatura) e para a formação continuada. Conselho Nacional de Educação, Brasília, Diário Oficial da União, 02 jul. 2015. Disponível em: <http://portal.mec.gov.br/busca?ordering=newest\&searchp hrase $=$ all\&limit=20\&areas[0] =tags\&searchword=resoluções $>$. Acesso em: 15 jun. 2016.

BRASIL. Diretrizes Curriculares Nacionais para a Educação das Relações Étnico-Raciais e para o Ensino de História e Cultura Afro-Brasileira e Africana. Brasília: Ministério da Educação, 2004.

BRASIL. Lei $\mathrm{N}^{\circ} 10.639$, de 9 de janeiro de 2003. Altera a Lei $\mathrm{N}^{\circ} 9.394$, de 20 de dezembro de 1996. Estabelece as diretrizes e bases da educação nacional, para incluir no currículo oficial da Rede de Ensino a obrigatoriedade da temática "História e Cultura Afro-Brasileira", e dá outras providências. Brasília: Congresso Nacional, 2003. Disponível em: $<$ http://www.planalto.gov.br/ccivil_03/leis/2003/L10.639.htm>. Acesso em: 15 jun. 2016.

CANDAU, V. M. F. Diferenças culturais, interculturalidade e educação em Direitos Humanos. Educação e Sociedade, Campinas, v. 33, n. 118, p. 235-250, jan./mar. 2012.

CANDAU, V. M. F. (Org.). Diferenças culturais e educação: construindo caminhos. Rio de Janeiro: 7 Letras, 2011. p. 13-33.

CARMINATI, R. S. Conselho de classe: reflexões da prática pedagógica. Disponível em: <http://www.webartigos.com>. Acesso em: 21 jun. 2016.

CAVALLEIRO, E. Do silêncio do lar ao silêncio escolar: racismo, preconceito e discriminação na educação infantil. São Paulo: Contexto, 2000.

COELHO, W. N. B.; PADINHA, M. S. R. Coordenadoras e práticas pedagógicas: legislação educacional, formação crítica e relações raciais. Linhas Críticas, Brasília, DF, v. 19, n. 38, p. 229-250, jan./abr. 2013.

COELHO, W. N. B.; SILVA, C. A. F. Preconceito, discriminação e sociabilidades na escola. Revista Educere et educare, v. 10, n. 20, p. 687-705, jul./dez. 2015.

CONCEIÇÃO, L. F. Coordenação Pedagógica e orientação educacional: princípios e ações em formação de professores e formação do estudante. Porto Alegre: Mediação, 2010. 
CRUZ, M. M. O.; CASTRO, S. B. D.; LIMA, A. C. R. E. Caminhos da coordenação pedagógica: uma análise histórica. 2009. Disponível em: <www.share.pdfonline.com>. Acesso em: 15 jun. 2016.

DAYRELL, J. A escola "faz" as juventudes? Reflexões em torno da socialização juvenil. Educ. Soc., Campinas, v. 28, n. 100 - Especial, out. 2007, p. 1105-1128.

DAYRELL, J. O rap e o funk na socialização da juventude. Educação e Pesquisa, São Paulo, v. 28, n. 1, p. 117-136, 2002. Disponível em: <http://www.scielo.br/>. Acesso em: 24 jun. 2016.

DAYRELL, J.; BARBOSA, D. “Turma ou panelinha?”: a sociabilidade de jovens alunos em uma escola pública. In: SOARES, L.; SILVA, I. O. Sujeitos da educação e processos de sociabilidade: os sentidos da experiência. Belo Horizonte: Autêntica, 2009. p. 237-268.

DICK, H.; FERREIRA, J. S.; CERVEIRA, L. A. Por onde navegam? Estudo sobre jovens e adolescentes do Ensino Médio de São Leopoldo e Novo Hamburgo. Cadernos IHU, ano 14, n. 53. São Leopoldo: Universidade do Vale do Rio dos Sinos, 2016. Disponível em: <http://www.ihu.unisinos.br/cadernos-ihu>. Acesso em: 15 jun. 2016.

DOURADO, L. F. Diretrizes curriculares nacionais para a formação inicial e continuada dos profissionais do magistério da educação básica: concepções e desafios. Educ. Soc., Campinas, v. 36, n. 131, p. 299-324, abr./jun., 2015.

DOWBOR, L. Tecnologias do conhecimento: os desafios da educação. Petrópolis, RJ: Vozes, 2001.

FAZZI, R. C. O drama racial de crianças brasileiras: socialização entre pares e preconceito. Belo Horizonte: Autêntica, 2004.

FRANCO, M. A. S. Coordenação pedagógica: uma práxis em busca da sua identidade. Revista Múltiplas Leituras, v. 1, n. 1, p. 137-131, jan. 2008.

FRIGOTTO, G. et al. (Org.). Ensino médio integrado: concepções e contradições. São Paulo: Cortez, 2005.

GATTI; B. A.; BARRETO, E. S. S.; ANDRÉ, M. E. D. A. Politicas docentes no Brasil: um estado da arte. Brasília: UNESCO, 2011.

GLATTER, R. A gestão como meio de inovação e mudanças nas escolas. In: As organizações escolares em análise. Lisboa: Dom Quixote, 1992. p. 139-161.

IANNI, O. A dialética das relações raciais. Estudos Avançados, São Paulo, v. 18, n. 50, abr. 2004.

MENDONÇA, M. L. M.; JORDÃO, J. V. P. Nojo de pobre: representações do popular e preconceito de classe. Contemporânea, v. 23, n. 23, ano 12, p. 1-18, 2014.

MÜLLER, T. M. P.; COELHO, W. N. B. A Lei n. 10.639/03 e a formação de professores: trajetória e perspectivas. Revista da $A B P N$, v. 5, n. 11, p. 29-54, jul./out. 2013. 
OLIVEIRA, E. S. G.; GRISPUN, M. P. S. Z. Princípios e métodos de supervisão e orientação educacional. Curitiba: IESDE; BRASIL S.A., 2013.

PERRENOUD, P. Avaliação: da excelência à regulação das aprendizagens? Entre duas lógicas. Tradução de Patrícia Chittoni Ramos. Porto Alegre: Artes Médicas Sul, 1999.

PLACCO, V. M. N. S.; ALMEIDA, L. R.; SOUZA, V. L. T. O coordenador pedagógico (CP) e a formação de professores: intenções, tensões e contradições. Revista Estudos e Pesquisas Educacionais, São Paulo, Fundação Victor Civita, n. 2, p. 225-285, 2011.

SAVIANI, D. Formação de professores: aspectos históricos e teóricos do problema no contexto brasileiro. Revista Brasileira de Educação, v. 14, n. 40, p 143-155, jan./abr. 2009.

SCHWARCZ, L. M. Nem preto nem branco, muito pelo contrário: coe e raça na intimidade. In: SCHWARCZ, L. M. (org.) História da Vida Privada no Brasil: contrastes da intimidade contemporânea. Vol. 4. São Paulo: Cia das Letras, 1998.

SERPA, D. Coordenador pedagógico vive crise de identidade. Edição especial "Os caminhos da coordenação pedagógica e da formação de professores". Fundação Victor Civita, Edição Especial, n. 6, jun. 2011.

SERRES, M. Polegarzinha: uma nova forma de viver em harmonia e pensar as instituições, de ser e de saber. Tradução de Jorge Bastos. Rio de Janeiro: Bertrand Brasil, 2013.

SETTON, M. G. Mídia e educação. São Paulo: Contexto, 2015.

Texto recebido em 03 de novembro de 2016.

Texto aprovado em 13 de abril de 2017. 